\title{
What I've Learned about Publishing a Book
}

\section{JAMES MULHOLLAND}

Many accounts that describe the procedures of academic writing focus on how authors can attract publishers by revising their dissertations so that they have appeal beyond their more narrow academic audiences. Few of these accounts, however, consider what happens when that process succeeds - that is, what happens to a manuscript after a publisher accepts it. This essay follows up on my 2011 JSP article, 'What I've Learned about Revising a Dissertation,' by considering those issues that arise during the production process of academic publishing. These stages are crucial for the success of a book, and they are avowedly collaborative in ways that differ from revising a dissertation. This process is often perceived as mere manufacturing when in fact it necessitates answering crucial conceptual questions. Furthermore, the customs and conventions of publishing are not a typical part of most academic training. In this essay, I draw from my own experience of publishing a title with an academic press to offer practical as well as theoretical reflections on how to select a publisher, write a book proposal, submit a manuscript, respond to readers' reports, think about copy-editing and proofreading, design a book jacket, and market a book after its physical publication.

Keywords: academic writing and revision, authorship, scholarly publishing, scholarly publishers, production and design, copy-editing, proofreading

This article seeks to inform authors - particularly first-time academic authors - about the overlooked details and unanticipated tasks that emerge during the production and publication of an academic book. It is a sequel (and companion) to my earlier article, 'What I've Learned about Revising a Dissertation.' ${ }^{\prime}$ In that article, I propose a number of different strategies for understanding how to turn a dissertation into a book, using the revision of my own dissertation as an example. I not only suggest how to conceptualize dissertation revisions but also offer some practical strategies to achieve them, such as how authors should organize their time, polish their arguments, control the evolution of their manuscripts, and create 'portable sentences' that other scholars will find 
useful and evocative-especially those scholars who evaluate manuscripts for academic presses.

The process of revising a dissertation into a manuscript is difficult. But it also overlaps with the skills commonly acquired during graduate training, which emphasizes scholarly traditions and innovation, conceptual argument and debate, and the organization of large quantities of evidence.

Such training, however, does not inform authors about the intricacies and conventions of the publication process - how to submit a manuscript to publishers, for example, or how to oversee a manuscript once it has been accepted by a publishing house. Like many first-time authors, I had focused on completing my book manuscript. Securing a contract was my primary goal; I rarely thought about what might happen after I achieved that goal. Publishing is the domain of publishers, I reasoned, and my role would be merely to advise on the production of my book.

I was wrong. As scholars, we focus so intently on argument and debate - on 'writing a manuscript' — that we forget how much of the creation of a book occurs while is it is being worked on at a press. Authors must remain intimately involved in the publication process after the submission and acceptance of a manuscript.

Furthermore, publishing a book is a collaborative process in ways that composing a manuscript need not be (though often is). Throughout the production process I was reminded of an assertion by the book historian Roger Chartier that authors do not write books. Instead, they compose texts, whereas the process of making books involves numerous other people, including printers, copy-editors, designers, and proofreaders, all of whom have distinct roles. ${ }^{2}$ To this assertion, I would add another reminder about the materiality of publication: Books are composed of more than unmediated argumentation. They are also physical (and virtual) objects. Understanding the materiality of books is enormously helpful for those authors who want to make informed decisions about the publication process.

This article therefore attempts to explain the lengthy publication process for academics. Academic publication differs significantly from commercial publication, of course, and I do not account for the differing demands of trade publishing. I also deal primarily with book publishing in the humanities and social sciences; the publication processes in the sciences, engineering, business, and law, while similar to that which I 
describe, contain disciplinary variations that may alter authors' strategies for publication. While there are numerous excellent books that decipher the intricacies of academic publishing, such as William Germano's Getting It Published or Beth Luey's Handbook for Academic Authors, I draw mostly on my experience publishing Sounding Imperial: Poetic Voice and the Politics of Empire, 1730-1820, which was released in 2013 by Johns Hopkins University Press. ${ }^{3}$ My contribution is the particularity of my experienceits difficulties, questions, and successes - which makes more precise the often more general reflections of commentators like Germano and Luey.

The perception of the academic publishing process is that it is detailoriented and tedious (at best). It is also viewed as a rapid (and perhaps demoralizing) shift after the intellectual efforts of conducting research and writing a manuscript; the former editor, academic, and publishing commentator Rachel Toor describes the publication process as akin to 'washing the dishes after a great dinner party.' While I follow the general chronology of this process, I do not focus on the stages themselves because publishers often supply detailed instructions about these steps. Instead, this article addresses the conceptual quandaries that often lurk in what otherwise may seem like mere manufacturing.

\section{SELECTING PUBLISHERS, COMPOSING A BOOK}

\section{PROPOSAL, AND PITCHING A MANUSCRIPT}

Writing a manuscript does not make a book. Rather, it leads to what might be considered the mid-point of the publication process, when an author is able to seek a wider audience by contacting publishers. The process of choosing publishers to contact can be confusing but, in general, most scholarly authors already have a sense of the presses that publish in their fields. For many, browsing the spines of their book collections identifies those presses that seem prominent in their fields.

The most important detail authors should understand about publishers - particularly academic publishers - is how they perceive the totality of their titles. Presses do not merely publish the best books they can find, nor do they simply seek out titles that might produce the greatest number of sales. Instead, academic presses attempt to produce coherence around the types of subjects in which they publish. It is not so much that they are specialized; rather, they are segmented.

By segmented, I mean that rarely does a publisher attempt to compete with every other press in all academic topics for market share. It is true 
that some presses, like Oxford University Press and Cambridge University Press, are vast but, in general, presses attempt to acquire distinct identities by associating themselves with particular fields. These associations subdivide the press and give it a range of identities that distinguish it, in the aggregate, from others. (For example, within the humanities, Oxford University Press and Cambridge University Press are strongly aligned with British literary and historical studies, while Duke University Press is known for queer theory and performance studies, Yale University Press for art history, and University of North Carolina Press for American history.) Most presses also contain book series devoted to particular topics, often edited by specialists within those fields. This is another way that editors attract authors and create identities for their presses.

Knowing these market segmentations and series is important (though not essential) when selecting where to send a manuscript. As I was completing my dissertation revisions, I created a list of presses to which I wanted to send my book proposal. However, I did not send my manuscript to all of the best-known presses at once. I did not feel comfortable querying presses more than once-no second chances - so I divided my list into three different stages. My rationale for staging my submissions was informed by the basic function of scholarly publishing. As Germano astutely argues, publishing, at its base, concerns 'selection and marketing.' 'Publishers choose,' he notes, and by choosing they 'extend their prestige to individuals by admitting them, and they draw their own prestige in turn from the people they admit. ${ }^{5}$ These symbiotic reputations are extremely important for understanding where to submit a book, and how to strategize that submission. Correctly or not, academics are judged as much by the quality of the press as the quality of their scholarship. For example, a close friend insists that any junior scholar should never seek to publish with a press that does not have 'university' in its title; nonuniversity publishers, he believes, indicate a lack of prestige and quality. I disagree, yet it is important for young scholars in particular to understand the hierarchies of academic publishing, and how much these hierarchies are nurtured not only by scholars' reputations but by publishers' reputations as well.

I was keenly aware of these hierarchies; to maximize my opportunities, I staggered what I thought of as the most prestigious presses across the three different stages to allow me to learn from rejections before moving on to the next stage. There remains a notion in academe that authors 
should query the 'best' presses first, and then move down a descending scale of prestige. I disagree strongly with this approach because it would not have allowed me to use rejections to improve my proposal.

The query itself is a highly conventional set of documents that, though routinized, still must capture an editor's attention and distinguish a manuscript from many others. Whenever I spoke socially with academic editors, they frequently mentioned the over-worked state of academic presses, which have reduced staff while requiring the evaluation of evergrowing numbers of manuscripts. One editor mentioned that he thought he received thirty to fifty proposals a week on average. As many previous commenters and advice-givers have noted, the proposal is fundamentally about convincing editors who may be skeptical about a scholarly project that it is both argumentatively sound and exciting while also being marketable.

Advice about book proposals often focuses on the emotive and the affective as much as on practical advice about structure and style. It is important to remember that editors are neither adversaries nor (in most cases) friends. This may seem elementary, yet because editors can have so much power over the reputations and careers of academics, the professional - even business-like - demands upon editors easily can be forgotten. ${ }^{6}$ As Niko Pfund, the president of Oxford University Press, notes, most skilled editors are 'generalists as much as specialists' whose duties require both intellectual and explicitly non-intellectual elements because they are 'in the business of saying no 19 out of 20 times. ${ }^{7}$ Indeed, editors often occupy the difficult position of acting as academic administrator, well-read intellectual, and businessperson. Analogies to dating are common in many accounts of submitting work to acquisition editors. ${ }^{8}$ Some commentators advise authors to translate the 'initial flush of enthusiasm' that made them interested in a scholarly project in the first place into the attitude of their proposal. ${ }^{9}$

All of this advice, while useful, often obscures the central, increasingly contradictory demand placed on academic projects: to be solid and methodical research that is also seductive and enticing, a work that demonstrates its intelligibility to already familiar markets that is nonetheless innovative and attractive to generalist editors and over-busy academic reviewers.

The book proposal plays a vital role in managing these contradictions by articulating them. It serves a gatekeeping function, indicating to editors 
that authors 'already know' something about the publication process (even if they do not). This is why formatting a proposal correctly is so important. Departures from established conventions present easy excuses for rejection. As with so many elements of an academic career, there is little formal training about these conventions. Soliciting numerous examples from successful peers and aggregating advice from friends and colleagues is essential. Some presses provide information about how they would like proposals to be formatted on their websites; however, never contact editors and ask them what they might want to know about a book. Before initial introductions, the expectation is that it is an author's responsibility to determine what might interest a press and how to create a proposal.

When submitting my proposal, I engaged in a two-step process. First, I queried editors over email. This email contained a statement of my academic affiliation, a brief (two- to three-sentence) description of my book, and a question about whether they would like to see my proposal. All the editors I contacted were interested, but their answers would not have mattered. I planned to send my proposal regardless of how they responded (or even if they did not respond). This introductory email was intended to alert them to my existence and to make my proposal slightly more memorable when they received it. Asking established scholars to contact their editors on behalf of first-time authors is also a successful way to approach publishers. Sometimes editors contact promising authors whose work they saw presented at conferences or published in journals.

After querying editors over email, my second step was to send a hardcopy book proposal. Emailing the documents for my proposal felt too ephemeral. (Some editors, however, like to receive electronic submissions. I asked their preference in my query email, but defaulted to paper submission if they did not express one.) I debated whether I should request meetings with editors at conferences or elsewhere. I did meet some editors briefly at conferences, but in general I think face-to-face meetings help only slightly, if at all, during the acquisition process. In fact, I think there is a chance that meeting requests, particularly from unknown or un-introduced scholars, may feel annoying to busy editors. My assessment is that meeting with editors can personalize an author, but it has little effect on the evaluation process. Editors are looking for strong proposals; an interesting interpersonal interaction might help, but it is the book proposal that is determinative. 
This means that enormous effort should be devoted to polishing the proposal. I wrote, shared, revised, and workshopped my materials extensively. My submission packet was fairly standard in that it included a cover letter, the proposal itself, and a sample chapter. The cover letter summarized my argument in four or five of the most attractive sentences I could write without repeating any of the language from my initial query email. This cover letter also described my project's status (that my manuscript was complete and ready for review) and it revealed why I had contacted that particular editor (most often because the press had published a title related to my topic).

Some presses indicate exactly how much material they desire as part of the submission process. Others do not. I included a single sample chapter in the packet. The sample chapter is meant to offer editors an opportunity to assess the state of a manuscript and to convey a sense of an author's intellectual acumen. It is standard to send the introduction, but I determined that sending my strongest chapter, regardless of its topic, was the best strategy. I also rejected the idea of sending more than one chapter, unless publishers asked for more. The publication process allows editors to ask for additional materials; patience is virtuous for authors, as is not overwhelming editors with eagerness.

Of all the materials in my submission packet, however, I agonized most over the proposal itself. Lengths varied among the other proposals I saw. One successful proposal was nearly thirty double-spaced pages, but most averaged five to eight single-spaced pages. The proposal should describe the scope of a book and argue concisely for its importance. Furthermore, the format of the proposal should indicate that the author is credible and mature. Demonstrating such credibility is why formatting the book proposal correctly is so crucial.

My proposal had six separate sections:

1. Overview

2. Chapter Synopsis

3. Author Biography

4. Competing and Complementary Titles

5. Market and Audience

6. Timeline

I included headings so that editors could move easily among each section. Much of the material in the project overview and chapter synopsis 
repeated writing I had composed for my academic job materials and my book's introduction. I plagiarized myself ceaselessly in my proposal.

Describing competing titles and assessing the book's market (sections 4 and 5), however, was a novel task. In these sections, I sought to convince editors that my book would attract readers. This forced me to acquire an alternative perspective of my work. I rejected the idea of advancing more typical claims - that there was no book on my particular subject or that my title would 'fill a gap' in the field-as insufficient. Publishers comprehend that books are not unique. In fact, I believe publishers perceive over-specialization as a detriment. In addition, while publishers, like academe, covet argumentative and methodological innovation, they are businesses too. I had to convince editors that there was a sufficient market for my book, not just that it articulated ground-breaking arguments.

In my section on competing and complementary titles, I mentioned earlier books - including one or two from the press I was soliciting, if possible - to convince editors that a market for my book already existed. I included titles of recent conferences and the names (and number of members) of special societies that might advertise or purchase my book. All these details were meant to demonstrate I had a clear-eyed assessment of my book's economic value. Academic editors, I realize now, are not attempting to find bestsellers in every proposal they read. Nor are they looking to publish simply because there has never been a book on a particular topic. Rather, they are looking to develop their titles, strengthen their press's reputation, and advance intellectual projects they find meaningful and intriguing ... without losing money. Addressing all aspects of this delicate algorithm makes for the most persuasive proposal.

\section{REVIEW, REVISIONS, AND READERS' REPORTS}

What happens after a manuscript is submitted is one of the more opaque elements of book publication. Most often, if publishers are interested after looking through an author's proposal, they will ask to see the entire manuscript, which likely will then be sent to one or more anonymous readers. This step is referred to as a manuscript 'being out to readers' or 'being under review.'

Reviewers perform the most vital part in determining whether a press will publish a book. While editors can often solicit reports from favourable academics, or even massage reports to make the acceptance of a book more likely, the academic review of a manuscript ultimately decides its 
fate. A press's readers serve as an important hurdle between an author and a published book. Negative reports, even for manuscripts that editors would like to champion, almost always halt a press's interest. Readers' reports are meant to provide an external evaluative function that constrains any individual editor's ability to make decisions based on personal relationships or favouritism.

My experience with academic reviews might be illuminating. I sent my manuscript to three presses, all three of which I had contacted over email. I had interest in my manuscript from two presses (I never heard anything from the third), and one press (my eventual publisher, Johns Hopkins University Press) elected to send my entire manuscript out for a single review report, as is standard at Hopkins Press.

As my narrative indicates, I never had to consider whether to submit my manuscript for review at multiple presses; Hopkins Press worked quickly after they showed their initial interest. However, I am agnostic about the idea of multiple submissions. The conventional understanding among academics is that editors do not mind multiple submissions until the review phase. Reviews often cost time and money, and an author who seeks reviews from multiple presses makes publishing professionals angry. Germano, a former editor and publisher, calls simultaneous submissions 'serious business' and compares it to 'bigamy. ${ }^{10}$ Yet even he acknowledges that there is a dangerous yet potentially beneficial strategy to simultaneous submission because of the competition it can create for a manuscript. I do not know any academics who submitted manuscripts for review at more than one press at the same time. Still, every academic has a friend whose manuscript has been under review for a year (or more!) without hearing an answer. The publication process is long, and I generally advised friends to stick with presses - particularly prestigious ones - if they had the time before tenure to do so. I myself determined the exact amount of time I could wait before I moved to my second and third stage of publisher submissions. If I had done so, I would have left my manuscript under review at those other presses but pushed ahead with newer ones as well. Positive reviews from one press might help to motivate a slower, but perhaps more desirable, publisher.

Happily for me, Hopkins Press was quick, efficient, and transparent about the review process. I received my review about six months after submitting my initial proposal. It was extremely positive but advised Hopkins Press to require revisions to the manuscript before accepting it 
for publication. I was thrilled to receive such a positive and detailed report. However, many manuscripts do not receive positive initial reports. One acquaintance of mine at an extremely selective private university in the South confessed that she had sent her book to nearly a dozen publishers before she finally placed it at an excellent press. Her story assuaged much of my early anxiety, as it suggested that initial rejections need not be reflective of any project's quality. Another academic colleague in English studies, who feels in retrospect that she submitted her manuscript before it was ready, received a scathing report from the first publisher she solicited. She describes the report from this elite press as having been 'mildly debilitating.' She received lukewarm reports from a second press before finally placing her manuscript with an excellent publisher whose evaluators spoke of it glowingly. The entire review process, she concedes, was 'very humbling.' And yet the negative reports were helpful, forcing her to assert the scope of her project and to explain more clearly what her book did not examine and why. Controlling the expectations for her project's archive was crucial; her additions seemed to prevent later evaluators from constantly querying why she was not working with this particular text or that specific author. In short, she grappled with these negative reports by revising her manuscript to erase what had been the objections of her initial readers.

In these two examples, it is impossible to know whether revisions to the proposal and the manuscript produced eventual success or whether these authors eventually found the right press for their projects. Regardless, their experiences with the review process are not uncommon. They required time, effort, and emotional balance to turn negative judgments into improved manuscripts and positive outcomes. Likewise, as I began to work with the report from Hopkins Press, I realized I had to reconsider my relationship to my book. The first step of this reconsideration was to assess the reader's suggestions and respond to the report in writing. The second more uncertain step was to complete the revisions and resubmit my manuscript to Hopkins Press.

\section{Responding to readers' reports}

Responding to readers' reports necessitates balancing between the two separate and exclusive requirements of academic writing: creating a book with as broad an audience as possible and producing a scholarly work that will satisfy one or two highly trained judges. These contradictions 
can be demanding, particularly when those readers remain unknown. Throughout, I felt it was important to trust the quality of my research and the lengthy process of composing a manuscript. And I found that I needed to cultivate a more nuanced attitude toward anonymous criticism by reacting impersonally to the reader's suggestions.

Most academic writers who have undergone the peer-review process likely understand it can be as much about managing emotions as it is about intellection. As Stephen Brookfield notes, 'Receiving requests for revisions is always upsetting, triggering a familiar cycle of emotions' from 'devastation' to 'impostorship' to 'recovery [and] anger' to 'a loss of energy and momentum.' ${ }^{\prime 1}$ While most authors may not feel the same intensity that Brookfield describes, he is correct that criticism in the peer-review process is 'typical' and 'unremarkable' because academe 'normalizes receiving feedback.' (He mentions, for example, that only one of his more than seventy published articles has been accepted without changes. $)^{12}$

Like many scholars, I have a tendency to react grumpily to criticism of my work. Knowing this, I reminded myself repeatedly to be analytical and dispassionate about the reviewer's advice. After I acknowledged the report, but before I wrote anything in response, I read the reader's report numerous times over the course of weeks. Taking time felt essential. The report required multiple readings before I could grasp the scope of its suggestions. For example, my reader encouraged me to delete my entire final chapter-one I had just finished before submitting my manuscript - because it seemed to be the beginning of a different project. With time, I realized that the reader was right, but at first I hesitated. I remembered all of the effort I invested in researching my final chapter's new archive and the time I devoted to that chapter's argument.

It was not wasted effort, however, and my emotional reaction inhibited a more reasonable and rational one. I had to remind myself of the good reasons why I wrote this final chapter: to broaden the scope of my book's topic in order to make my manuscript more appealing to academic editors. My initial reaction to the report had been emotional rather than intellectual.

The reader's report encouraged me to emphasize argumentative consistency instead of my appeals to a wider audience. To me, this encapsulates the different motives of reviewers and acquisitions editors. Editors seek smart books that sell well. Reviewers care less about sales and more 
about argument and scholarship. I had to balance all of these concerns as I considered my response. This involved assessing where I was in the publishing process. The chapter my reviewer suggested deleting had been composed to expand the scope of my project and thus convince editors to send it out for review. That had already been accomplished. Therefore, I had to admit that my personal attachment to this chapter was not a sufficient reason to maintain it against the reader's advice. Neither was the 'sunk cost' of the effort I had expended. My hesitancy about altering my project was founded more on my habits and routines than on coherence and argument. As my example shows, responding to readers' reports involves more than simply understanding the comments and comprehending new argumentative positions. It also requires that the author develops a new attitude toward criticism of the book.

After I had come to this new understanding - an emotional as much as a scholarly attitude - I felt prepared to respond to the reader's report. Most presses require authors to compose a letter that addresses readers' concerns and outlines potential revisions. These revisions should be described in broad, rather than detailed ways. For example, I offered to compose a coda to my book to substitute for the final chapter I was deleting. I used a few sentences to describe what might be included in that coda. More detail was not necessary and might even have seemed obtrusive. My editor wanted merely to see that I had a plan for how to address the reader's concerns, rather than to understand the intricacies of that plan.

Perhaps most importantly, I explained in my response what suggestions I would not accept from the reader. As a fellow academic in queer theory has noted, the trick is to turn everything — even criticism - into a strength. Luckily for me, there were very few points with which I disagreed; my reader's report was a genuinely helpful analysis of my book. Still, I think it is important, as a policy, to object to at least some items of the report. These objections may be small, but they consolidate an author's independence in the face of others' critiques.

My response, therefore, was the first step toward absorbing the reviewer's advice into my own manuscript. Like the book proposal, the response to reader's report should be highly conventional. Positive tone and attitude are imperative, even when disagreeing; an author's response to the report can circulate widely, including among editors, editorial boards, as well as the readers themselves. There is no reason to seem 
aggressive, hostile, or defensive. Throughout my letter, I emphasized the reader's positive statements and my (genuine) appreciation for his or her efforts, while outlining what changes I would make in my manuscript because of the report. By being assertive, systematic, and clear, I hoped to present myself as a mature authority on the subject of my book.

\section{Revising after readers' reports}

The most useful part of responding to the reader's report was that it forced me to map out exactly how I planned to pursue my revisions. I printed out the reader's report and my response and numbered each section, marking up the report much as I would a text I was about to teach in class. Each numbered section was a step in the process of revision. I turned my reader's report into a revision checklist.

Mapping out these steps was essential because, as I mentioned in my earlier article, controlling the evolution of a project is the central task of revision. While revising my dissertation, I broadened the scope of my research. As I revised for publication, however, I narrowed and sharpened that scope to accommodate the reader's review.

Perhaps the greatest impediment to my revisions, however, was my lack of enthusiasm. I was exhausted from composing the manuscript, and regaining energy to make further changes was painful. I felt my book was done, but I was being asked to be eager about making what had been a long process even longer.

These sentiments, I knew from revising my dissertation, were natural for a long project, so I followed the same advice I had devised then. One evening, I simply started the revision process by completing a minor change that the reader had suggested. The momentum from making this small adjustment shattered the sense that my manuscript was a fragile object that I did not have the stamina to alter again. After I completed this change, I was under way.

The revisions were not onerous, but to retain my enthusiasm for my book, I limited the amount of time I spent on my manuscript when it was in someone else's (the reader's or my editor's) hands. I began a second project and remained preoccupied with it while others read my manuscript. The production process normally entails long periods of waiting while others complete their work, followed by intense bursts of maximal effort. I avoided creating work for myself on my book so that I would feel rejuvenated when new changes needed to be made. 
My experience revising in response to readers' reports suggests that authors' reactions to readers' reports can be driven as much by emotion as concepts. This is not to deny that there are poor readers who determine too much about the fate of scholars' books, or publishers who overlook an excellent manuscript because of them. But in my experience, these types of unsatisfied and inconsolable reviewers are uncommon. Instead, it is authors who must be careful that their judgments do not become confused with an accounting of all the effort and time they have invested in a manuscript. It is important to know when to stop revising, but simple tiredness with the process is not a strong indicator that revisions are complete.

Most of all, responding to and revising from readers' reports required me to admit that my manuscript was unfinished and able to be improved, even though I simply wanted the process to be over. Still, the majority of the answers to the reader's questions were already in my manuscript (similar to what happened during the last stage of my dissertation revision). Instead of seeing the reader's suggestions as an impediment, I learned to trust that reader as another collaborator and find ways to un-submerge those answers that my research and writing had already discovered.

\section{NEGOTIATING CONTRACTS}

After completing my revisions after the reader's report, I returned the manuscript to my editor, who then passed my revised manuscript back to the reader for final approval. It is often at this stage when initial contracts become finalized ones, though this differs according to the press. Some presses offer both 'advanced' contracts and final ones. Hopkins Press did not, instead issuing one contract but noting that my manuscript needed to be complete and accepted by the press's board before my book would be published.

Contracts can be worrisome documents, and I spent a lot of time trying to decode its language before finally asking my editor to explain it to me. This is one area of the publishing process where authors can announce their lack of knowledge without hesitation. Most editors understand and will explicate their press's policies on contracts. ${ }^{13}$

Many aspects of a publisher's contract — such as royalties, advances (if any), and number of copies printed (also known as a book's 'print run') - are fairly non-negotiable, unless there is more than one press 
competing for a book. This is especially true for some smaller academic presses. The small university press of one friend in eighteenth-century studies had outsourced its production to a larger commercial publisher. She ultimately declined the larger publisher's commercially focused copyediting, opting instead to pay for her own academic copy-editor. In this situation, she noted, there was little leeway for her to negotiate with her publisher about her contract.

Although her example shows that contract flexibility differs depending on the publisher, there are a few items of a contract that every author should ask about and comprehend thoroughly. The most important, particularly for first-time authors who may also be up for tenure, is when the press has a 'commitment to publish' - when it is contractually committed to publishing a book.

Two other elements to understand are book format and illustrations. The book format concerns whether a book appears in paperback, in cloth (also known as 'hardcover'), or both. Most academic books appear first in cloth, to be reprinted later as a paperback depending on initial sales. This is the situation for my book. Some presses offer simultaneous paper and cloth formats for first-time authors - particularly in more contemporary fields where the publisher thinks a cheaper paper edition might increase sales - but in my experience this is rare. Determining the format of your book can be significant because it can determine the viability of book sales over the long term.

Many academic presses also publish electronically - either in formats available for download or in electronic copies available for institutional readers like ebrary. My book appeared in electronic formats, and while I do not know the breakdown in sales, I cannot help but think electronic publishing is an important additional venue extending the reach of scholarly books, particularly to institutions wary of housing physical copies in libraries.

In addition to the book's format, the other major contract concern is illustrations, which can be an expensive additional cost when publishing a book. I was lucky to have Hopkins Press cover the cost of the seventeen illustrations in my book. I made sure this was stipulated explicitly in my contract, and I would encourage others to do the same, if possible, because the payment of this expense by the press is otherwise not guaranteed.

Furthermore, Hopkins Press covered only the cost of physically reproducing images for the book. As is consistent with most presses' policies, 
I was responsible as the book's author to secure permission to reproduce images. This can be a lengthy and confusing process, particularly for authors working with contemporary materials that are still under copyright when there is often both an owner of the physical object and an owner of the intellectual content.

My illustrations were not nearly as complex as those of friends who are art historians. (One friend in modernism began a Kickstarter campaign to crowd-fund the cost of her permissions, offering individual guided tours of art museums as an incentive to donate. ${ }^{14}$ ) Nonetheless, securing images and permissions necessitated meticulous documentation; Hopkins Press required evidence that I had secured both print and electronic reproduction rights for every image. In some cases, these rights were narrowed to North America and western Europe. Some libraries asked about translation details and numbers of copies to calculate their price. Some offered reduced rates for academic titles or waived everything but processing fees.

I learned too late in the process to shop around. Most of the illustrations I included were passages from rare books held in multiple libraries. These passages needed to be photographed-most often by libraries themselves - as high-resolution digital images. (Make sure to acquire the highest resolution possible. Book designers can always convert to lower resolution should they need to, but not the other way around.)

What each library charged varied widely - both for producing images and securing the right to publish that image. A friend I know from graduate school, who also works in literary studies, found the Library of Congress was the least expensive. In my experience, smaller, less-trafficked collections and libraries had fewer fees, and many even waived them: They were happy to have me publicize their collections with my writing. The most salient detail to understand about managing a book's illustrations is that the process can be time-consuming. Start early-as soon as it appears a press is interested in publication. I required six to eight months in total to acquire all of the necessary images and permissions.

COPY-EDITING, PROOFREADING, AND PAGE PROOFS

After the manuscript revisions were complete and the contract was finalized, my book went into production. By the time the production process started, I had spent many years imagining my book in quite specific ways. This vision proved important because it helped me determine how 
much I was willing to compromise. Academic publishing involves a lot of standardization; I sought to maximize my opportunities to retain the personality of my writing and my project.

Retaining such personality can feel especially difficult during the copyediting phase. As my copy-editor noted, the goal of copy-editing is twofold: consistency and clarity. Her sentiment reflects the general attitude inculcated by copy-editors toward the correction process. Janet Mackenzie argues that 'copyediting is the heart of the editorial process, comprising the essential tasks that must be done to prepare any document for publication. ${ }^{15}$ She notes that as she edits she asks a series of questions about each sentence. These questions assess whether the sentence adds to the clarity of the book, is situated in the right place, is written in a way that is comprehensible, and functions in an orderly fashion with the writing that surrounds it. ${ }^{16}$

I was not prepared for how time-consuming it would be to achieve these goals of consistency and clarity. As my book's production advanced, I realized that the focus on its details increased as well. Before I had focused primarily on the features of the written prose. During the production phase, I needed to attend to the formatting of the book as well - including the headings, sub-headings, and chapter titles - to the table of contents, to page numbers within the text (and, eventually, in the index), and to the cover.

Because of the proliferation of design details, effective proofreading is even more crucial at this stage. I had my manuscript proofread throughout the production process, ideally by strangers but just as often by myself. Each round of proofreading felt like a defeat. I was nearly paralyzed with anxiety when, while I was correcting my proofs - the final stage before the physical production of a book-I noted that I had misspelled the name of an important literary critic in one section and had incorrectly identified the title of an important work in another section of my book.

I mention this merely to reinforce that while the goal of copy-editing is consistency and clarity, it is impossible to produce books without errors. Throughout the process, I reminded myself of an anecdote recounted to me by Jerome McGann, an English professor at the University of Virginia, where I had been an undergraduate. He mentioned how a colleague, who had produced an edition of William Wordsworth's long poem The Prelude, received a fresh copy of the newly published book and excitedly opened it to a random page, only to discover an error. McGann related 
this story to advocate for the flexibility of hypermedia archives, which would have allowed this error to be corrected. But now that I have published a book, I take the anecdote to mean something else as well: No book is error-free. The goal of copy-editing is consistency and clarity because error-free publications are unachievable.

Being reconciled to the presence of errors in the final product does not mean that the process of proofing and correcting a manuscript should not be robust. Early on in the production process, I proofread when I did not have other intellectually demanding work. That changed when I realized how engaged I needed to be. Proofreading and correcting copy-edits are not simply the blunt brute work of repetitive reading. Remaining attentive and intellectually engaged is essential.

Such attention was particularly important for me when I was correcting copy-edits. Like many first-time authors, I had received little line editing when I published articles or chapters. The majority of comments concerned scholarly issues, rather than stylistic or structural ones. This changed markedly when I received the first round of copy-edits. My manuscript was returned to me with a waterfall of comments and corrections, arranged in the nearly illegible coloured formatting of Microsoft Word's 'Track Changes' function. As I scrutinized my copy-editor's suggestions, my first reaction was concern. I had expected extensive copy-edits (in fact, thorough attention to detail was a real attraction of Hopkins Press), but I immediately realized the scope of the issues involved. Copy-editing was not merely the correction of grammatical issues but another opportunity to rewrite my book.

This exemplifies the tense relationship that can be raised at this stage of the production process. A close friend who studies graphic narratives and comics told me that copy-editing her manuscript had been the most stressful two weeks of her career. I had always assumed that her stress was due to the sheer amount of effort required to check an entire book in such a short time, but I realize now that there is a powerful emotional and intellectual component as well.

For example, my copy-editor and I spent a great deal of time debating the tenses of my prose. Like many literary critics, I most often write in the present tense. To me, this created a sense of energetic action and it accurately reflected the way literary critics analyse still-existent literary objects. My copy-editor objected, claiming that the use of the present tense for past writers created confusion. We ultimately agreed on how 
to separate historical events and past actions from those that should be described in the present tense, but these changes altered the tone of my book (ultimately for the better).

Most copy-editors are keenly aware of authors' anxieties about others changing their prose. This concern has been persistent; in 1981, Judith Butcher advised copy-editors to be delicate with authors' sentiments, admitting that 'how far one should correct an author's style is a matter of judgment' that 'depend[s] on the author's reactions to one's proposal. ${ }^{17}$ In her description, the author becomes someone whose emotional state must be closely monitored. I suspect that neither authors nor publishers would blame Butcher for her abundance of caution, but I think of the changes my copy-editor suggested were a result of her perspective. I believe she recognized more than I did the differences between a wordprocessed document and a book in its final printed form. I was used to reading other scholars' writing in printed books, but not my own, which I nearly always encountered in the word processor. My copy-editor could anticipate how to illuminate the important aspects of my argument as my book became more compact on the cramped printed page. She removed significant amounts of signposting and other descriptive accounts of my argument. The resulting transitions felt abrupt to me, but for her my signposting was unnecessary clutter. In a printed book, readers trust the integrity of a chapter's sections and the relevancy of its section breaks without need of explanation. This is a revealing example of how to copy-edit and revise for consistency and clarity, rather than for style or to preserve the habits of an author.

Of course, like anonymous readers, copy-editors are fallible. An author must be the ultimate arbiter of the book's form (within economic constraints), particularly because copy-editors, despite their experience with publishing, generally do not have expertise in the topic of any individual book. It was important for me to be sure that my book retained some sense of the intellectual position and argument I wanted to make. Some answers to abstract conceptual questions were difficult to articulate, so there were moments when I sacrificed the clarity of my prose to the honesty of my position.

Copy-editing is also the stage when an author is required to master the details of his or her book's format, especially its visual presentation. Every detail must be verified, particularly pertaining to the cover and the table of contents, which serve as the two significant entry points for a 
book. Some authors are not involved in the design of their books' covers. I simply assumed I was. I would encourage every author to participate actively in the design of a book cover until instructed otherwise. Be persistent, even pushy; the cover design in particular felt important to me because - together with the title-it would be the recognizable feature of the book. Therefore, I identified an image I wanted to use on my cover - a painting that dramatized the action of a poem I analysed in my book - and passed it along to my editor. I also included a number of cover designs from other books as models.

Whether my thoughts on the cover were useful, I do not know, but Hopkins Press did select the image I suggested for the cover. More importantly, the press designed a cover that is visually arresting. I do not believe that a book's cover needs to be an articulation of its argument, as one art historian friend claimed it should be. Few read covers as elements of a scholarly argument. The cover is a conduit to a book's argument rather than an encapsulation of the argument itself. But, as Stephanie Shields notes, often it is not a book's cover that sells it, but rather the reproduction of the book in promotional materials. She was advised to pick a cover image that would look sharp in advertising because 'the only place the cover ever shows up in its actual size and color is on the book itself. ${ }^{\text {'18 }}$

Instead of the book cover, it is the table of contents that should summarize the argument of a book. I devoted a great deal of thought to my table of contents. I insisted on the inclusion of all of my chapter's subheadings in the table of contents as the chapter titles felt too short to provide enough information about each chapter's materials. Scanning through these chapter titles and sub-headings would alert readers, I hoped, to those sections of the book they wanted to read and use. In short, I tried to amalgamate the identifying functions of the table of contents with the searching function of an index. Few scholars read books from beginning to end, so I felt it was essential for readers to immediately understand what might be relevant to them when they flipped open my book.

After all of the copy-edits were completed, there was a concluding round of corrections called 'page proofs.' The page proofs provide a representation of the book in its final form. It is also the last chance for changes. Some presses, like Hopkins, lay out a formula that determines the total number of changes that can be made during the page proofs stage, because changes can be costly. 
As I corrected the page proofs, I did not focus on that number. Instead, I made a detailed list of all changes, most of them small corrections of typos or grammar. There were issues of legibility, as I attempted to match the page proofs with the copy-edited pages - which themselves had two sets of changes in two different colours - to ensure that all the corrections had been made. Some authors print out these pages, but with electronic copies it becomes increasingly difficult to do so. This is a stage in which a large screen, or multiple monitors, would be useful. It is surprising how many small details can slip by the eyes of even attentive readers.

A book is an enormous collection of dense information organized rhetorically and visually. Formal consistency is hard to create and errorfree books are nearly impossible. The copy-editing, proofreading, and page proofs phases of book production offer multiple opportunities for authors (and other readers) to look deliberately at different levels of the book, from the minutiae of commas and periods to the more conceptual issues of argument. For me, it was also the first time that I made a concerted effort to theorize about and refine the visual presentation of my book. My attention was increasingly drawn to the front and back matter of the book - the copyright page and table of contents, for examplewhich are generally not thought of as argumentative. Each of these elements - and each of these levels - demanded dispassionate critical attention.

There is no easy way to maintain this attention and enthusiasm after the exhaustions of composing a manuscript, soliciting publishers, revising in response to readers' reports, and enduring the copy-editing and page proof stages. Earlier in this article I advocated for starting a new project, and I think in the final stages of my book's production this new project was essential. It changed my attitude toward my book, making it my 'first book' rather than my only book. This new attitude made the book feel like it was part of the past, which I found to be an effective way to achieve some perspective on the many questions that arose during the production process.

\section{MARKETING}

I have suggested that the editorial and production parts of book publication are not well aligned with the typical training of academe. Marketing is even more remote from that training. Few academics write books exclusively for money; instead, books are composed for scholarly reasons 
and for professional promotion within academe. To write books for money is still seen as somewhat shameful, which can make knowing how to market them tricky as well.

This attitude means that strategies of book publicity are not often discussed among academics. I remember a friend advising me early in the process to look for a publisher who would 'support' my book. He felt his own press had not sustained enough interest in his work to publicize his first book effectively.

Many academics likely understand this desire for support from publishers, in the form of publicity, even as those same academics are often resigned to the idea that their books will be met with what another friend in English studies laughingly notes is 'resounding silence.'

I did not consider marketing at all as I composed my manuscript and I did not feel able to ask my editor to discuss Hopkins Press's marketing plans for my title while my manuscript was still being reviewed. In retrospect, I still do not think I would; it feels presumptuous. Perhaps this attitude is at odds with the attitudes of those who are not first-time authors or who have developed relationships with presses and editors. And though many authors likely feel as my friend did, I wondered how I would even know if Hopkins Press did or did not support my book.

Hopkins Press has always been responsive and enthusiastic, actively seeking to make my book as widely known as possible. My book appeared in their New Titles catalogue for the Spring 2013 season; this catalogue is among the most important marketing devices for publishers. The book was featured on Hopkins Press's Web site, and I wrote a post for their JHU Press Blog. I saw that my book appeared as part of a Hopkins Press ad in the New York Review of Books.

Regardless, I recognize now the way that scholarly attention and publicity overlap in uncomfortable ways. It is not that sales make specific books more or less important. Rather, I think I now recognize that the goals of marketing are persistence and visibility, and I understand that, despite my reservations, I have an important role in creating this persistence and visibility. Of course, when copies of my book finally appeared in the mail-a moment I had been anticipating for years-I was so blissful that I did not want to think about how to publicize my book. To this day, I am too afraid to ask about sales figures.

My attitude toward marketing is fairly common among academics. ${ }^{19}$ Contrary to popular portrayals of academics as elitist, preening 
know-it-alls — or the opposite: stumbling, absent-minded bores-most academics are smart and inviting, yet shy about their work. The primary domain of our research, particularly in the humanities, is among students in the classroom and scholars in our conferences. We think of our published books as now-separate entities that must make their own way in the world, based entirely on their merits. To participate zealously in a book's publicity feels like awkward self-promotion.

This attitude, while detrimental, is hard to dislodge. Despite my reservations about self-promotion, I announced my title on Facebook, started an Academia.edu page, and featured it prominently on my almost trafficfree personal Web site. But as a more senior colleague in eighteenthcentury studies informed me, the marketing process was not only crucial, it was something that should continue long after the book was published. Most of her techniques were practical and detailed, such as creating a personal Web site, soliciting attention from related blogs, or contacting relevant scholarly societies. Other advice was inventive and unusual. She noted, for example, that she sent her books to her alma maters and used their alumni networks as publicity mechanisms. She encouraged me to include the name of my book in my email signature so that everyone with whom I corresponded would see the title. She asked her publisher to send copies of her books to every conference she attended. If the publisher could not send copies, she asked for fliers with her books' information and purchasing discounts. She also insisted that publicity results from persistence, particularly in the form of contacting and encouraging my press. Similarly, another friend in eighteenth-century studies emailed her colleagues in academe, asking them to have their institution purchase a copy of her book. She noted that a number of smaller libraries own her book because of these requests. She also attended conferences overseas to publicize her book specifically to the non-American audiences that she encountered more rarely in her academic travels. She was gratified when she attended a small conference and many of the participants had already purchased and read her book.

Such tactics share two important features. The first is the importance of visibility. Whether it is advertising in newspapers and journals, sending fliers to conferences, or promoting titles through Web sites, the most crucial aspect of book publicity is being sure that others are aware that the title even exists. Drawing attention to the book allows it to argue for its own relevance and importance. Initial visibility is an important first step. 
The second feature of such tactics is the strong connection between author and book, particularly after the book's release. My colleagues oriented me toward a new conceptualization of publicity: using my career as a means of driving sales. Ultimately, I think their examples suggest authors need to become an argument for their books. During the final stages of the production process, we should separate ourselves from our manuscripts as a way to acquire the necessary critical distance to make dispassionate decisions. After publication, however, books become the most identifiable parts of academic careers. One's books are a kind of academic passport. Therefore, I thought, not only should I promote my career with my book, I should promote my book with my career by being sure to refer to it and circulate its ideas. I have to do more than hope that others come in contact with those ideas now that they are in print.

Of course, equating authors and their books has a long history in English literature, part of which I study in my book. The eighteenthcentury English poet Thomas Gray saw his poems as his children and his publisher as their father (making him their mother). These metaphors are common in the history of English literature; a book, once born, is seen as separate from its creator, but still knotted together by an unusual kind of umbilical. Despite being so familiar with this history, I still feel reluctant. Now that I have shifted from composing a manuscript to helping it through production and now to aiding the press in marketing it, I realize my book, perhaps like a child, still requires my attention for a little bit longer.

James mulholland is an assistant professor of English at North Carolina State University. His book, Sounding Imperial: Poetic Voice and the Politics of Empire, 17301820 (Johns Hopkins University Press 2013) uncovers an eighteenth-century experimental tradition of poetry that mediates oral voices and foreign speakers. His next project, Literary Calcutta, traces the emergence of a regionally distinct Englishlanguage literary tradition in the late eighteenth-century Indian Ocean world.

NOTES

1. J. Mulholland, 'What I've Learned about Revising a Dissertation,' Journal of Scholarly Publishing 43, 1 (October 2011): 39-51

2. R. Chartier, The Order of Books: Readers, Authors and Libraries in Europe between the Fourteenth and Eighteenth Centuries. Trans. L. G. Cochrane (Stanford: Stanford University Press 1994), 9-10 
3. W. Germano, Getting It Published, 2nd Edition: A Guide for Scholars and Anyone Else Serious about Serious Books (Chicago: University of Chicago Press 2008); and B. Luey, Handbook for Academic Authors, 5th ed. (Cambridge: Cambridge University Press 2010)

4. R. Toor, 'Selling Your Book and Yourself,' Chronicle of Higher Education (February 14, 2011), available at http://chronicle.com/article/Selling-Your-BookYourself/ $126346 /$

5. Germano, Getting It Published, 24

6. See, for example, A. Glatthorn, Publish or Perish: Strategies for Writing Effectively for Your Profession and Your School (Thousand Oaks: Corwin 2002), 89-90.

7. N. Pfund, 'Career Alternatives: Thinking about Scholarly Publishing?' Chronicle of Higher Education (4 September 1998), available at http://chronicle.com/article/ Career-Alternatives-Thinki/46437/

8. Germano jests that 'selecting a publisher is less like proposing marriage and more like cadging a dinner invitation' (Getting It Published, 46).

9. For more on proposal writing, see R. Toor, 'How to Write a Good Book Proposal,' Chronicle of Higher Education (11 February 2013) available at, http://chronicle.com/ article/The-Reality-of-Writing-a-Good/137207; and R. Toor, 'How to Write a Good Book Proposal, the Sequel,' Chronicle of Higher Education (8 October 2013), available at http://chronicle.com/article/How-to-Write-a-Good-Book/142183/. Toor's best advice is to 'work backward' from the marketing questionnaire that most academic publishers have for each of their authors, using the answers to the questions there about market, audience, and readership as inspiration for the book proposal.

10. Germano, Getting It Published, 56, 55

11. S. Brookfield, 'Addressing Feedback from Reviewers and Editors,' in T. S. Rocco and T. Hatcher, eds., The Handbook of Scholarly Writing and Publishing (San Francisco: Jossey-Bass 2011): 251-61; 252-3

12. Ibid., 253

13. For an excellent general overview of the legal and economic features of contracts, see Luey, Handbook for Academic Authors, 71-90.

14. See http://www.kickstarter.com.

15. J. Mackenzie, The Editor's Companion, 2nd ed. (Cambridge: Cambridge University Press 2011), 161. James Hartley similarly argues that copy-editors improve manuscripts 'by their practiced attention to detail — which most authors do not have'; see J. Hartley, Academic Writing and Publishing: A Practical Handbook (New York: Routledge 2008), 149. I do not agree with Hartley's assessment that authors lack attention to detail, though I do think copy-editors offers a new perspective on a book project that is likely too familiar to its author. 
16. J. Mackenzie, The Editor's Companion, 167. Scholarly examinations of the consequences of copy-editing seem to be inconclusive about the degree to which copyediting alters the substance of academic arguments. See, for example, E. Wates and R. Campbell, 'Author's Version vs. Publisher's Version: An Analysis of the Copy-Editing Function' Learned Publishing 20, 2 (April 2007): 121-9; and D. Goodman, S. Dawson, and J. Yaremchuk, 'Open Access and Accuracy: AuthorArchived Manuscripts vs. Published Articles’ Learned Publishing 20, 3 (July 2007): 203-25.

17. J. Butcher, Copyediting, 2nd ed. (Cambridge: Cambridge University Press 1981), 18

18. S. Shields, 'When a Book Cover Speaks Volumes' Chronicle of Higher Education (6 June 2003), available at http://chronicle.com/article/When-a-Book-CoverSpeaks/2943/

19. For more on this attitude and advice about how to combat it, see Toor, 'Selling Your Book and Yourself.' 